\title{
LANDAU-KLEFFNER SYNDROME
}

\section{Study of four cases}

\author{
Lúcia H. Coutinho dos Santos ${ }^{1}$, Sérgio A Antoniuk?', \\ Marcelo Rodrigues², Sílvio Bruno², Isac Bruck ${ }^{1}$
}

\begin{abstract}
We describe four patients with clinical features of Landau-Kleffner syndrome and discuss electroencephalographic features, treatment and prognosis. Anticonvulsants and prednisone were used for treatment with good control of seizures in all cases and a less effect response in acquired aphasia. Further studies are necessary to elucidate the causes and management of this syndrome.
\end{abstract}

KEY WORDS: Landau-Kleffner syndrome, electroencephalogram, prednisone, language, children, aphasia.

\begin{abstract}
Síndrome de Landau-Kleffner: estudo de quatro casos
RESUMO- Descrevemos quatro pacientes com achados clínicos de síndrome de Landau Kleffner. São discutidos os aspectos relacionados aos achados eletrencefalográficos, tratamento e prognóstico. Anticonvulsivantes e prednisona foram os principais métodos terapêuticos utilizados com controle das crises convulsivas em todos os casos e resposta variável quanto a afasia adquirida. Mais estudos são necessários para elucidar as causas e o manejo desta síndrome
\end{abstract}

PALAVRAS-CHAVE: síndrome de Landau Kleffner, eletroencefalograma, prednisona, afasia, linguagem, criança.

Landau Kleffner syndrome (LKS) or acquired epileptic aphasia was first described by Landau and Kleffner in 1957 with the report of six children with convulsive disorders and acquired aphasia'. The aphasia is a language regression in the form of a verbal auditory agnosia in a previously normal child, usually 3 to 9 years old, and is the first clinical manifestation in $50 \%$ of cases. At least $70 \%$ of children have simple or complex clinical seizures, and/or atypical absence seizures and $100 \%$ have alterations in the electroencephalogram (EEG). We describe four chidren with clinical features of LKS.

\section{CASES}

Case 1. A white male, first child, was born in September 1987. Pregnancy, birth history and developmental milestones were unremarkable. In 1992 he started to present a nocturnal generalized tonic-clonic seizure of more than 30 minutes duration and subsequently repeated, always during his sleep. His speech became garbled. Neurologic examination was unremarkable except for the speech deficit. Formal auditory tests were inconclusive, but he was considered to have an aphasic disorder. An EEG taken in March 1994 showed multifocal spike dis- charges and the patient was started on phenobarbital. One month later ( April 1994) he had 2 generalized seizures. Speech comprehension and production became progressively worse, and were accompanied by increasing irritability. Prednisone $(2 \mathrm{mg} / \mathrm{kg} / \mathrm{d})$ was then started and since the beginning of treatment with this drug, no generalized seizures have occurred. Also, the patient showed improvement in understanding short sentences but with little recovery of speech. His EEG showed lentification but without paroxismal spikes. Two months later, the dose of prednisone was decreased and phenytoin was instituted, with the patient being free of seizures. In March 1998, after 3 years without a crisis, with good speech recovery, with the patient in the third year of elementary school and with the disappearance of the paroxysmal discharges in the EEG, Phenytoin was tapered off. In December 2000 he was 13 years old and enrolled in sixth grade of elementary school, his communication had improved although he needed reinforcement in Portuguese.

Case 2. A white female, first of two children, was born in September 1990. Pregnancy and birth history were unremarkable. She was a healthy infant, sat at about five months, and walked at 15 months. She spoke some words at 16 months. Behavioral and development milestones

Centro de Neuropediatria (CENEP) do Hospital de Clínicas da Universidade Federal do Paraná (UFPR), Curitiba PR, Brasil: ${ }^{1}$ MD, Child Neurologist, Professor of Pediatric Department of UFPR. ${ }^{2}$ MD, Resident of Child Neurology.

Received 21 August 2001, received in final form 24 October 2001. Accepted 8 November 2001.

Dr. Isac Bruck - Rua Floriano Essenfelder 81 - 80060-270 Curitiba PR - Brasil. 
were also unremarkable. In 1995, at the age of four years, she had a febrile seizure for about three minutes. After that episode her speech became garbled and she became irritable. She was hospitalized in June 1995 and her neurologic examination was normal except for the deficit in language. She was considered to have an aphasic disorder, primarily receptive. Her EEG showed continuous spikes and spike-wave complexes on the left side. Carbamazepine was started. She returned to the neuropediatric clinic only in May 2000 at the age of nine years, without medication since the last trimester of 1995 and was free of seizures. She was in the second year of elementary school and also participated in a privy class (second grade of elementary school) with improvement in her communication. A conventional audiometric test and BERA were normal.

Case 3. A white female, first of two children, was born in February 1984. Pregnancy and birth history were unremarkable. She was a healthy infant and walked at 9 months. She started to speak between 9 and 12 months. Mental and motor development was also unremarkable. In January 1988 her speech became progressively garbled, with communication mainly through signs and when she was four years old, October 1988, a neurologic examination was unremarkable except for the deficit in speech. Formal auditory tests were inconclusive, but the patient was considered to have an aphasic disorder. Her EEG showed multifocal spike discharges. Phenobarbital was started. In September 1990 she suffered a generalized tonic-clonic seizure. Her communication was only through signs and she was having more difficulty in understanding what was said to her. Her electroencephalogram was unchanged and she continued to be treated with phenobarbital. In August 1991, she had a second generalized tonic-clonic seizure and her communication got worse. Prednisone $(2 \mathrm{mg} / \mathrm{kg} / \mathrm{d})$ was started with control of seizures and with improvement of communication. In October 1991, the EEG normalized and prednisone was tapered off. Since then she did not return to the neuropediatric clinic.

Case 4. A black male, the younger of four children, was born in March 1995. Pregnancy and birth history were unremarkable. He was a healthy infant, sat at 8 months, walked at 15 months and spoke normally at 22 months. Motor and mental development was also unremarkable. In September 1999 he had a generalized febrile seizure while sleeping. Subsequently he had two more generalized febrile seizures and speech became garbled. Neurologic examination was unremarkable except for the deficit in speeech. An electroencephalogram showed a mild slow activity without any spike discharges. Prednisone
$(2 \mathrm{mg} / \mathrm{kg} / \mathrm{d})$ and valproic acid were started. In January 2000 he was free of seizures and improved his communication and was able to speak some sentences. In March 2000, prednisone was tapered off and valproic acid was maintained. He remained in good condition without seizures and with a better hability to communicate.

\section{DISCUSSION}

LKS has been reported in association with neurocysticercosis ${ }^{2}$, Haemophilus influenzae type B meningitis ${ }^{3}$, temporal lobe tumor ${ }^{4}$, demyelinating lesion ${ }^{5}$ and cerebral arteritis ${ }^{6}$. An autoimmune etiology has been proposed ${ }^{7}$, but in most cases there is no evident causal factor, as observed in the present cases.

Aphasia in LKS has a fluctuating course with remission occurring spontaneously or due to drug action, but total recovery is uncommon. Three patients persisted with mild language deficit and the last one was studying in a school for the deaf. One hypothesis is that the language deficit is caused by interictal epileptiform discharges (IED) which prevent appropriate involution of synaptic pathways at critical stages of brain development. The activation of IED in LKS seems to be more sensitive to the neural mechanisms, inducing spindles that are active during sleep induction, at sleep onset and at the beggining of each cycle. An immature brain associated with an altered metabolic regional pattern and with the hypersynchronizing function of nonREM sleep may lead to regional cortical excitability $^{8}$. Some investigators consider the epileptiform abnormalities an epiphenomenon reflecting underlying brain pathology ${ }^{9}$.

Electroencephalography (EEG) usually consists of various patterns including continuous slow spikewave discharges during sleep ( $85 \%$ or more of the deep sleep recording), focal sharp waves with spikes, and centro temporal spikes ${ }^{10}$. Despite the easy control of clinical seizures in most affected children, the EEG is generally resistant to the effects of anticonvulsant medications. In our cases we had 2 EEG with multifocal spike discharges, 1 with continuous spikes and spike-wave complexes, and one with mild slow activity, but in this case we didn't have a more prolonged EEG during sleep.

There is an overlapping betwen LKS and autistic regression (before the age of 24 months), continuous spike-wave syndrome of slow-wave sleep ${ }^{11}$, rolandic epilepsy with speech dyspraxia/opercular syndrome $^{12}$, and cognitive regression with occipital epileptiform discharges ${ }^{13}$, some of them called variants of LKS. All the patients reported here had normal 
language development until at least 24 months, ruling out autistic regression. None of the patients had any findings of the other syndromes mentioned, making the diagnosis of LKS the most plausible one.

The treatment of LKS is controversial. Anticonvulsants such as valproic acid, sulthiame, ethosuximide and benzodiazepines usually control seizures but have a variable effect on language recovery. Some investigators reported that an improvement in speech was often concurrent with a similar improvement in EEG response, while others have argue against a direct relationship between the two ${ }^{14}$. A ketogenic diet ${ }^{15}$, immunoglobulin ${ }^{16}$, calcium-channel blockers ${ }^{14}$, multiple subpial transection surgery ${ }^{17}$, and corticosteroids ${ }^{18}$ are the therapeutic methods that can be useful for LKS. Some anticonvulsants such as phenobarbital, carbamazepine and phenytoin have been reported to be innefective or even harmful ${ }^{19}$. Two of our patients had control of seizures and EEG improvement with prednisone, one with prednisone and valproic acid and Case 2 had a good outcome without medication. Other authors ${ }^{19-20}$ have also found that steroids may be useful for treatment, resulting in improved speech, suppression of seizures and normalization of the EEG. We also cannot exclude the possibility that improvement in our cases might have been due to the natural history of the disease, since spontaneous remissions sometimes occur, as in Case 2.

In summary, LKS is an intriguing disorder that must be considered in cases of acquired aphasia. More research is necessary to elucidate the physiopathology of the syndrome, as well as the choice of more effective treatment.

\section{REFERENCES}

1. Landau WM, Kleffner FR. Syndrome of acquired aphasia with convulsive disorder in children. Neurology 1957;7:523-530.

2. Otero E, Cordova S, Diaz F, Garcia-Teruel I, Del Brutto OH. Acquired epileptic aphasia (the Landau-Kleffner syndrome) due to neurocysticercosis. Epilepsia 1989;30:569-572.

3. Ansink BJJ, Sarpathie H, Van Dongen HR. The Landau-Kleffner syndrome: case report and theoretical considerations. Neuropediatrics 1989;20:170-172.

4. Solomon GE, Carson D, Pavlakis S, Fraser R, Labar D. Intracranial EEG monitoring in Landau-Kleffner syndrome associated with left temporal lobe astrocytoma. Epilepsia 1993;34:557-560.

5. Perniola T, Margari L, Buttiglione M, Andreula C, Simone IL, Santostasi R. A case of Landau-Kleffner syndrome secondary to inflammatory demyelinating disease. Epilepsia 1993;34:551-556.

6. Pascual-Castoviejo I, Lopez-Martin V, Martinez-Bermejo A, PerezHigueras A. Is cerebral arteritis the cause of Landau-Kleffner syndrome? Four cases in childhood with angiographic study. Can J Neurol Sci 1992;19:46-52.

7. Connoly AM, Chez MG, Pestronk A, Arnold S, Mehta S, Deuel R. Serum autoantibodies to brain in Landau-Kleffner variant, autism, and other neurologic disorders. J Pediatr 1999; 134:607-613.

8. Nobili L, Baglietto MG, Beelke M, et al. Spindles-inducing mechanism modulates sleep activation of interictal epileptiform discharges in the Landau-Kleffner syndrome. Epilepsia 2000;41:201-206.

9. Holmes H, McKeever M, Saunders Z. Epileptiform activity in aphasia of childhood: an epiphenomenon? Epilepsia 1981;22: 631-639.

10. Aicardi J. El síndrome de Landau-Kleffner. Rev Neurol 1999;29:380 385.

11. Djabraian A, Batista MAS, Lima MM, Silva DF. Continuous spike-waves during slow waves sleep. Arq Neuropsiquiatr 1999;57: 566-570.

12. Roulet E, Deonna T, Despland PA. Prolonged intermittent drooling and oromotor dyspraxia in benign childhood epilepsy with centrotemporal spikes. Epilepsia 1989;30:564-568.

13. Nass R, Gross A, Devinsky O. Autism and autistic epileptiform regression with occipital spikes. Dev Med Child Neurol 1998;40: 453-458.

14. Mantovani JF. Autistic regression and Landau-Kleffner syndrome: progress or confusion? Dev Med Child Neurol 2000;42:349-353.

15. Bergqvist AGC, Brooks-Kayal AR. Ketogenic diet in the treatment of acquired epileptic aphasia. Ann Neurol 1997;42:504.

16. Mikati M, Saab R. Successful use of intravenous immunoglobulin as initial monotherapy in Landau-Kleffner syndrome. Epilepsia 2000;41:880-886.

17. Robinson RO, Baird G, Robinson G, Simonoff E. Landau-Kleffner syndrome: course and correlates with outcome. Dev Med Child Neurol 2001;43: 243-247.

18. Tsuru T, Mori M, Mizuguchi M, Momoi M. Effects of high-dose intravenous corticosteroid therapy in Landau-Kleffner syndrome. Pediatr Neurol 2000;22:145-147.

19. Marescaux C, Hirsch E, Finck S. et al. Landau-Kleffner syndrome: a pharmacologic study of five cases. Epilepsia 1990;318:768-777.

20. Lerman P, Lerman-Sagie T, Kivity S. Effect of early corticosteroid therapy for Landau-Kleffner syndrome. Dev Med Child Neurol 1991;33:257-260. 